\title{
Thermal Stability of Electrochemical-Hydrothermal Hydroxyapatite Coatings
}

\author{
Keith Savino, Matthew Z. Yates* \\ Department of Chemical Engineering and Laboratory for Laser Energetics, University of \\ Rochester, Rochester, NY, 14627, United States.
}

\begin{abstract}
Dense, uniform hydroxyapatite (HA) coatings were synthesized by hydrothermal crystal growth onto titanium substrates that were electrochemically seeded with HA nanocrystals. The HA was also doped with yttrium and/or fluoride during the hydrothermal reaction. The resulting HA coatings have a unique morphology consisting of crystal domains aligned with the crystallographic $c$-axis oriented normal to the surface of the coating. At elevated temperatures, the HA coatings were found to slowly decomposes via dehydroxylation to $\beta$-tricalcium phosphate $(\beta$-TCP). Thermal decomposition negatively impacts the mechanical stability of the coating and can negatively impact performance in vivo due to the higher solubility of $\beta$-TCP relative to HA. It is shown that thermal decomposition of HA membranes can be avoided by adding water vapor to suppress dehydroxylation during thermal processing, or by doping the membrane with fluoride during hydrothermal synthesis. Thermal decomposition of HA coatings to $\beta$-TCP was characterized by X-ray diffraction and scanning electron microscopy. Coatings of HA or yttrium-doped HA were found to be unstable in dry air above $600{ }^{\circ} \mathrm{C}$, but stable in a steam atmosphere at $900{ }^{\circ} \mathrm{C}$. Coatings doped with fluoride or co-doped with yttrium and fluoride were also thermally stable in dry air at $900{ }^{\circ} \mathrm{C}$. Therefore, the unique HA coating morphology and composition can be maintained during post-synthesis thermal processing or high temperature applications.
\end{abstract}

Keywords:

Hydroxyapatite, Hydrothermal, Thermal stability, Fluoride

${ }^{*}$ Corresponding author

Email address: myates@che.rochester. edu (Matthew Z. Yates) 


\section{Introduction}

Hydroxyapatite (HA) is a crystalline phase of calcium phosphate having the stoichiometric formula of $\mathrm{Ca}_{10}\left(\mathrm{PO}_{4}\right)_{6}(\mathrm{OH})_{2}$ with either monoclinic or hexagonal crystal symmetry [1]. The mineral component of teeth and bone tissue consists of HA that is partially substituted with other atoms at the calcium, phosphate, and hydroxyl positions in the crystal lattice [2,3]. Given its structural and compositional similarity to natural bone mineral, synthetic HA has been extensively studied as a bone substitute, orthopedic implant coating, and drug delivery carrier [4-11]. Hydroxyapatite is a brittle material, so it is often applied as a coating on metal for load bearing applications. The HA coating provides bioactivity, corrosion resistance, and biocompatibility, while the metal provides mechanical strength. A variety of coating methods are available, including plasma spray, sol-gel synthesis, biomimetic approaches, and electrochemical crystallization [12-17]. The chemical composition and morphology of the coating varies greatly depending on the synthesis conditions. Coatings are typically polycrystalline with randomly oriented crystal domains, and may contain impurities of other amorphous or crystalline calcium phosphate phases. Synthetic HA crystals are often nonstoichiometric in which the relative amounts of calcium, phosphate, and hydroxyl groups vary while the HA crystal structure is maintained. In addition, HA is readily doped with other ions that greatly affect the physical, chemical, optical, and electrical properties of the material. For example, doping with strontium, magnesium, and other ions has been shown to enhance bone growth near the HA surface $[18,19]$. Fluoride doping increases chemical and structural stability [20-22]. Europium doping creates fluorescent HA crystals [23]. Yttrium doping has been shown to enhance high temperature proton conductivity of HA ceramics [24, 25].

Recently, a novel multi-stage coating method was developed that combines electrochemical and hydrothermal crystallization [26, 27]. A very short electrochemical crystallization is carried out in the first stage in order to seed a metal surface with HA nanocrystals. In the second stage, extended hydrothermal crystal growth onto the seeded substrate results in a dense coating. The electrochemicalhydrothermal method results in a unique HA coating morphology in which all of the crystal domains are aligned with the crystallographic $c$-axis normal to the metal surface. During the hydrothermal crystallization step, the coating may be doped with carbonate, magnesium, yttrium, and other ions [28, 29]. The method was shown to be superior to electrochemical synthesis alone in producing uniform coatings [27]. The unique morphology of the coating was shown to enable enhanced high temperature proton conductivity and permanent electrical polariza- 
tion $[25,26,30]$. Unlike other coating methods, the surface is exclusively covered by crystallographic c-planes. The control of the HA crystal plane exposed to surrounding fluid may prove valuable in biomedical applications [31].

At temperatures above $\sim 300^{\circ} \mathrm{C}$, HA becomes proton conductive via a mechanism of proton hopping along the linear columns of hydroxyl groups along the crystallographic $c$-axis [32]. The high temperature proton conductivity has led researchers to investigate novel uses of HA in applications such as sensors, ion conducting membranes, and electrets [32-35]. In dry air, it has been shown that the proton conductivity is slowly lost due to dehydroxylation [36]. The decrease in proton conductivity at high temperature can be an indirect measurement dehydroxylation, as the loss of hydroxyl groups eliminates the proton conduction paths. For HA that is deficient in calcium relative to the stoichiometric composition, dehydroxylated HA forms according to the reaction [37]:

$$
\begin{aligned}
\mathrm{Ca}_{10-z}\left(\mathrm{HPO}_{4}\right)_{2 \mathrm{z}}\left(\mathrm{PO}_{4}\right)_{6-2 \mathrm{z}} & \\
& \rightarrow \mathrm{Ca}_{10-\mathrm{z}}\left(\mathrm{P}_{2} \mathrm{O}_{7}\right)_{\mathrm{z}-\mathrm{s}}\left(\mathrm{PO}_{4}\right)_{6-2 \mathrm{z}+2 \mathrm{~s}}(\mathrm{OH})_{2(1-\mathrm{s})}+(\mathrm{z}+\mathrm{s}) \mathrm{H}_{2} \mathrm{O}
\end{aligned}
$$

The dehydroxylated HA will then decompose to a mixture of $\beta$-tricalcium phosphate $\left(\beta-\mathrm{Ca}_{3}\left(\mathrm{PO}_{4}\right)_{2}, \beta-\mathrm{TCP}\right)$ and stoichiometric $\mathrm{HA}$ :

$$
\begin{aligned}
\mathrm{Ca}_{10-\mathrm{z}}\left(\mathrm{P}_{2} \mathrm{O}_{7}\right)_{\mathrm{z}-\mathrm{s}}\left(\mathrm{PO}_{4}\right)_{6-2 \mathrm{z}+2 \mathrm{~s}}(\mathrm{OH})_{2(1-\mathrm{s})}+(\mathrm{z}+\mathrm{s}) \mathrm{H}_{2} \mathrm{O} \\
\rightarrow(1-\mathrm{z}) \mathrm{Ca}_{10}\left(\mathrm{PO}_{4}\right)_{6}(\mathrm{OH})_{2}+3 \mathrm{zCa}_{3}\left(\mathrm{PO}_{4}\right)_{2}+(\mathrm{z}-\mathrm{s}) \mathrm{H}_{2} \mathrm{O}
\end{aligned}
$$

The dehydroxylation process is accelerated the more calcium deficient the HA is, with dehydroxylation occurring as low as $500{ }^{\circ} \mathrm{C}$ [37]. Decomposition to $\beta$-TCP is detrimental for applications that exploit ion conduction of $\mathrm{HA}$ since the complete loss of hydroxyl groups will eliminate the proton conduction path, and the $\beta$-TCP formation will introduce grain boundaries that block proton conduction [32, 36, 38]. Dehydroxylation can also be problematic upon sintering of HA coatings for biomedical applications since the decomposition byproducts can dissolve in vivo faster than pure HA [39].

In the present study, calcium deficient HA and yttrium-doped HA coatings were synthesized by the electrochemical-hydrothermal method. Then two techniques were investigated for their ability to enhance high temperature stability of the coatings by suppressing dehydroxylation. Heating the coatings in a steam environment rather than dry air was used to increase thermal stability as the water 
vapor can drive reaction (1) above to the left [36]. Thermal stability was also enhanced by substituting a fraction of the hydroxyl groups in HA with fluoride during hydrothermal crystallization. Fluoride-doped HA (FHA) is more resistant to decomposition to $\beta$-TCP at elevated temperatures, as the fluoride ions interfere with the dehydroxylation process [40-43]. By preventing dehydroxylation, the unique HA coating morphology obtained by electrochemical-hydrothermal synthesis can be maintained after thermal processing, potentially opening up new applications for the material.

\section{Experimental Procedure}

\subsection{Materials}

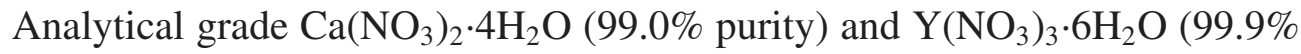
purity) were purchased from Alfa Aesar. $\left(\mathrm{NH}_{4}\right)_{2} \mathrm{HPO}_{4}(>99.0 \%$ purity) was purchased from EMD. $\mathrm{K}_{2} \mathrm{HPO}_{4}$ (99.99\% purity), $\mathrm{CaCl}_{2} \cdot 2 \mathrm{H}_{2} \mathrm{O}$ (99+\% purity), $\mathrm{NaCl}$ ( $>99.0 \%$ purity), tris(hydroxymethyl)-aminomethane (99.8+\% purity), disodium ethylenediaminetetraacetate dihydrate $\left(\mathrm{Na}_{2}\right.$ EDTA $\left.2 \mathrm{H}_{2} \mathrm{O}\right)(99.0-101.0 \%$ purity), and $\mathrm{NH}_{4} \mathrm{~F}$ (98\% purity) were all obtained from Sigma-Aldrich. 36.5-38.0\% hydrochloric acid and 28.0-30.0\% pure ammonium hydroxide were purchased from Mallinckrodt Chemicals. Detergent powder was purchased from Alconox. Titanium(Ti) substrates ( $12.5 \mathrm{~mm} \times 12.5 \mathrm{~mm}$ and $0.89 \mathrm{~mm}$ thick) and platinum foil ( 25 $\mathrm{mm}$ x $25 \mathrm{~mm}$ and $0.127 \mathrm{~mm}$ thick) were purchased from Alfa Aesar. Deionized water was used for all solutions.

\subsection{Electrochemical Crystallization}

Titanium substrates were polished with $\mathrm{SiC}$ paper ( 800 grit) to provide surface roughness. The substrates were then thoroughly washed with Alconox detergent powder, rinsed with tap water, attached to a silver wire by tightly wrapping the wire through a drilled hole in the substrate, sonicated in an ethanol/acetone (volume ratio $=1: 1)$ solvent for 30 minutes, and then rinsed with deionized water.

An electrolyte solution was prepared containing $\mathrm{NaCl}(138 \mathrm{mM}), \mathrm{CaCl}_{2}(1.25$ $\mathrm{mM}), \mathrm{K}_{2} \mathrm{HPO}_{4}(0.828 \mathrm{mM})$, and tris(hydroxymethyl)-aminomethane $(50 \mathrm{mM})$ in $125 \mathrm{~mL}$ deionized water. The solution was adjusted to $\mathrm{pH} 7.2$ using hydrochloric acid. The electrolyte solution was then heated to $95^{\circ} \mathrm{C}$. During heating, the solution was covered to minimize evaporative loss of water. The substrate and a platinum plate were held parallel to each other with a fixed distance of separation of $10 \mathrm{~mm}$. The substrate and platinum plate were connected to the negative 
and positive outlets, respectively, of a direct current power supply (Instek GPS3030D) and immersed in the electrolyte solution. The electrochemical reaction was carried out for 5 minutes at a constant current density of $12.5 \mathrm{~mA} / \mathrm{cm}^{2}$ (relative to the platinum plate area), then rinsed off with deionized water and dried in air.

\subsection{Hydrothermal Crystallization}

A solution of $\mathrm{Na}_{2}$ EDTA $2 \mathrm{H}_{2} \mathrm{O}(0.115 \mathrm{M})$ in $30 \mathrm{~mL}$ of deionized water was stirred for 30 minutes so that it was completely dissolved. $\mathrm{Ca}\left(\mathrm{NO}_{3}\right)_{2} \cdot 4 \mathrm{H}_{2} \mathrm{O}(0.1$ $\mathrm{M})$ was then added, followed by $\left(\mathrm{NH}_{4}\right)_{2} \mathrm{HPO}_{4}(0.06 \mathrm{M})$. For yttrium doped hydroxyapatite (YHA), $\mathrm{Y}\left(\mathrm{NO}_{3}\right)_{3} \cdot 6 \mathrm{H}_{2} \mathrm{O}(0.01 \mathrm{M})$ was added. For fluoride doped hydroxyapatite (FHA), $\mathrm{NH}_{4} \mathrm{~F}(0.02 \mathrm{M})$ was added. For yttrium and fluoride codoped hydroxyapatite (YFHA), both $\mathrm{Y}\left(\mathrm{NO}_{3}\right)_{3} \cdot 6 \mathrm{H}_{2} \mathrm{O}(0.01 \mathrm{M})$ and $\mathrm{NH}_{4} \mathrm{~F}(0.02 \mathrm{M})$ were added. The standard HA synthesis solution had no added fluoride or yttrium. The $\mathrm{pH}$ of each solution was raised to 10.0 with ammonium hydroxide and then stirred for about 10 minutes. The electrolyte solution was then transferred to a Teflon-lined stainless steel pressure vessel (Parr Item No. 4744, $45 \mathrm{~mL}$ internal volume), and filled with approximately $30 \mathrm{~mL}$ solution. The substrate electrochemically coated with HA nanocrystal seeds was submerged in the solution with the seed layer facing down and tilted $\sim 45^{\circ}$ relative to the bottom of the vessel. The vessel was heated to $200{ }^{\circ} \mathrm{C}$ for 10 hours at autogenous pressure. After 10 hours, the vessel was cooled to room temperature in a fume hood, and then the sample was taken out, rinsed with deionized water several times, and dried in air.

\subsection{Thermal Processing}

Samples were placed into a tube furnace (Thermo Scientific, Lindberg/Blue M) for 3 hours at a set point temperature of $600,700,800$, or $900{ }^{\circ} \mathrm{C}$. The ramp rate for heating and cooling was $2{ }^{\circ} \mathrm{C} /$ minute with the heating beginning and ending at room temperature. For samples heated in steam, a peristaltic pump (Gilson, Minipuls 3) delivered a steady supply of water at a flow rate of $7 \mathrm{~mL} /$ minute through the alumina tube containing the sample. The pump was turned on when the temperature of the furnace reached $200{ }^{\circ} \mathrm{C}$, then turned off when it cooled below $200{ }^{\circ} \mathrm{C}$.

\subsection{Materials Characterization}

The composition of HA membranes was determined by energy-dispersive Xray spectroscopy (EDX). Three spots on each sample were probed at $15 \mathrm{kV}$ and 

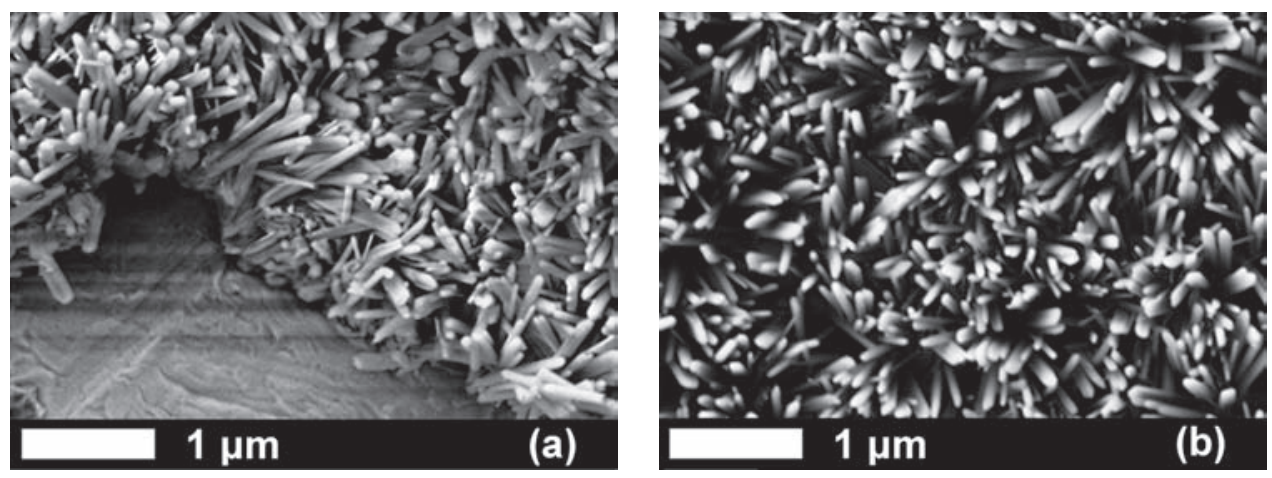

Figure 1: Electrochemically synthesized HA seed crystals: (a) side view (b) top view.

the average values and standard deviations were calculated. The crystal structure of HA was determined by X-ray diffraction (XRD) (Philips PW3020) with $\mathrm{Cu} \mathrm{K} \alpha$ radiation $(\lambda=1.54056 \AA)$ from $2 \theta=20-40^{\circ}$ with a step rate of 0.02 degrees/second. Phase identification was made by comparison with the Joint Committee on Powder Diffraction Standards (JCPDS) files. Relative intensities were calculated using X'Pert Data Viewer software. Crystal morphology was examined using a scanning electron microscope (SEM, Zeiss-Auriga) with an accelerating voltage of $3 \mathrm{kV}$.

\section{Results and Discussion}

Hydroxyapatite nanocrystals were deposited onto titanium substrates through electrochemical crystallization in order to form a seeded surface to use in subsequent hydrothermal crystal growth. Figure 1 shows a typical HA layer that is formed after 5 minutes at $95^{\circ} \mathrm{C}$ with an electrical current density of $12.5 \mathrm{~mA} / \mathrm{cm}^{2}$. The thickness of the HA layer is roughly $500-800 \mathrm{~nm}$, while the width of each crystal is about 20-25 nm. In the side view image shown in Fig. 1(a), some of the HA was removed with a blade in order to show the film thickness and underlying substrate. The electrochemical synthesis results in a uniform coating of nanocrystals of HA. The same electrochemical seeding conditions were used for all samples. The HA nanocrystals seeds act to promote crystal growth on the titanium surface during the secondary hydrothermal crystallization step.

Four types of samples were synthesized by hydrothermal crystallization onto the seeded substrate: hydroxyapatite (HA), fluoride-doped (FHA), yttrium-doped (YHA), and HA co-doped with yttrium and fluoride (YFHA). Each sample was 
synthesized in a single hydrothermal crystallization reaction at $200{ }^{\circ} \mathrm{C}$ for 10 hours. Hydrothermal crystallization onto the seeded substrates results in larger crystals that are aligned on the surface with the $c$-axis normal to the substrate [26]. The crystals are also easily doped during hydrothermal synthesis by adding reagents containing the desired dopant $[28,29]$. The composition of the resulting samples was examined by EDX, as shown in Table 1. EDX and electron microprobe analysis confirmed the presence of yttrium and fluoride in the doped samples FHA, YHA, and YFHA. Yttrium concentration was confirmed using electron microprobe analysis since the yttrium and phosphorous EDX peaks are very close. The calcium to phosphorous $(\mathrm{Ca}: \mathrm{P})$ ratio was found to be below the stoichiometric value of 1.67 for all samples, indicating the product is non-stoichiometric calcium deficient hydroxyapatite that is typical from hydrothermally synthesis [44]. For samples doped with yttrium, the ratio $(\mathrm{Y}+\mathrm{Ca}): \mathrm{P}$ was used in Table 1 because $\mathrm{yt}-$ trium atoms substitute for calcium in the crystal lattice.

\begin{tabular}{llllll}
\hline Sample & Ca [At\%] & P [At\%] & Y [At\%] & F [At\%] & (Ca+Y):P \\
\hline HA & $61 \pm 0.9$ & $39 \pm 0.9$ & - & - & $1.54 \pm 0.06$ \\
FHA & $56 \pm 1.4$ & $34 \pm 0.1$ & - & $9.5 \pm 1.4$ & $1.62 \pm 0.04$ \\
YHA & $54 \pm 0.9$ & $39 \pm 0.6$ & $6.4 \pm 0.6$ & - & $1.55 \pm 0.04$ \\
YFHA & $49 \pm 1.4$ & $34 \pm 1.1$ & $6.1 \pm 0.6$ & $11 \pm 2.0$ & $1.62 \pm 0.07$ \\
\hline
\end{tabular}

Table 1: Composition of samples as determined by EDX and EMA.

Representative side view images of all four types of samples synthesized hydrothermally onto the seeded titanium substrate are shown in Fig. 2. For the un-doped HA shown in Fig. 2(a), the crystals are $10 \mu \mathrm{m}$ in length and 1-2 $\mu \mathrm{m}$ in width with hexagonal facets visible on the upper surface. The longest axis of the crystals is the $c$-axis, so the SEM image indicates preferential orientation of the $c$-axis normal to the titanium substrate. With fluoride doping, the crystals are again $\sim 10 \mu \mathrm{m}$ in length and have a maximum width of $\sim 2 \mu \mathrm{m}$, as shown in Fig. 2(b). The fluoride doped samples have flatter and more sharply defined hexagonal facets on the upper surface and a broader distribution of crystal widths with a larger fraction of the crystals smaller in width than those observed in un-doped HA. Yttrium doping suppresses growth along the $c$-axis in favor of growth perpendicular to the $c$-axis [28]. As a result, the yttrium doping results in a more dense coating, as shown in Fig. 2(c). Although some of the crystal domains are fused together, individual hexagonal facets are still visible on the upper surface. The yttrium doped crystals are wider than un-doped HA, and the coating thickness is significantly reduced to $\sim 5 \mu \mathrm{m}$. The sample co-doped with yttrium and 

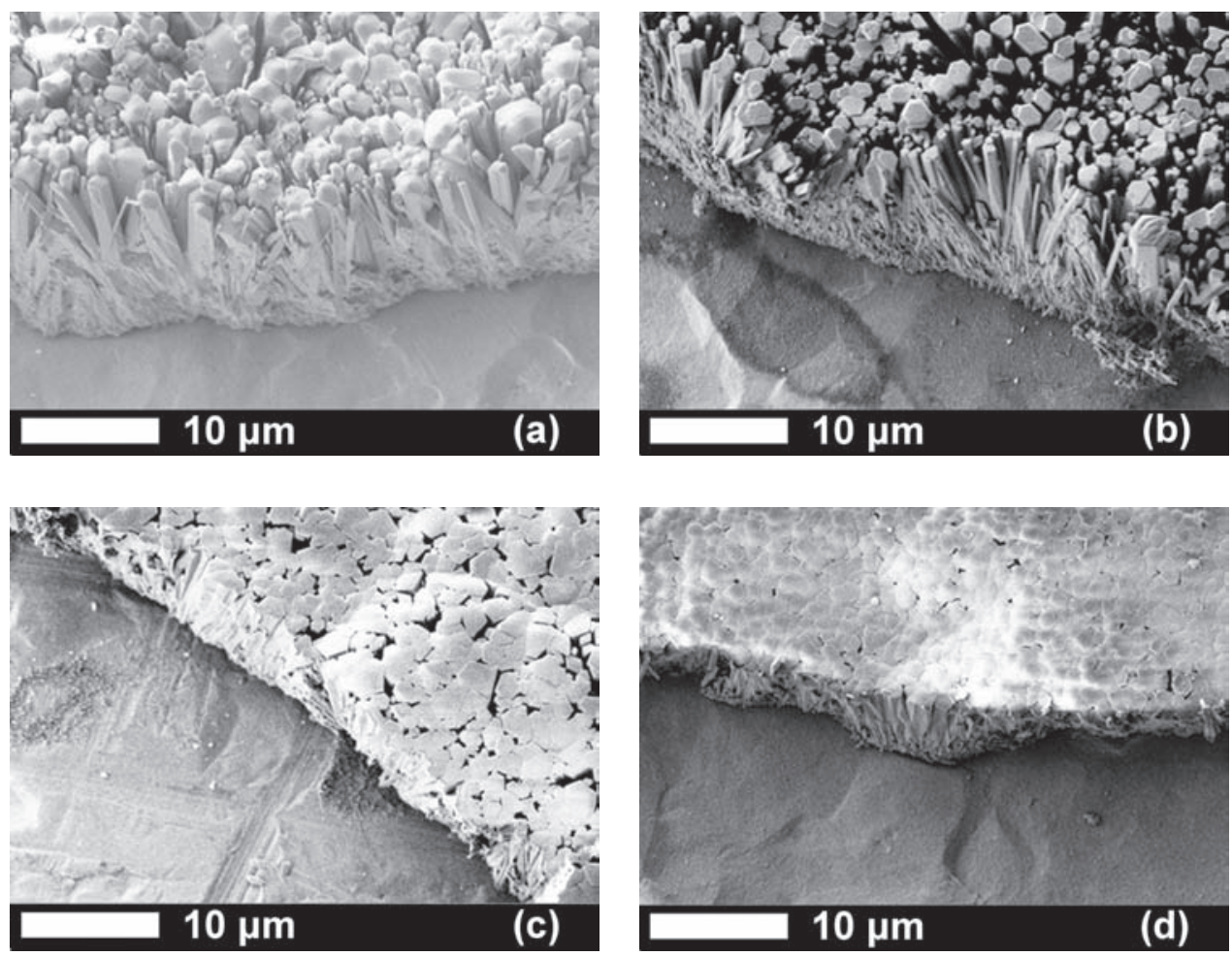

Figure 2: Side view images of hydroxyapatite that was hydrothermally crystallized onto the seeded titanium surface: (a) hydroxyapatite (HA), (b) fluoride-doped HA (FHA), (c) yttrium-doped HA (YHA), and (d) HA co-doped with yttrium and fluoride (YFHA).

fluoride, shown in Fig. 2(d), reveals a similar morphology to the yttrium doped sample except that the majority of the crystal domains are fused together to form a coating that is nearly fully dense.

The crystal structure of the four samples shown in Fig. 2 was probed with XRD. A representative XRD pattern is shown in Fig. 3 for the un-doped HA. The most distinct feature of the XRD pattern is the very large enhancement in intensity of the $\left(\begin{array}{lll}0 & 0\end{array}\right)$ peak, which is consistent with the preferential orientation of the $c$-axis normal to the substrate. All other peaks were identified as belonging to HA or the underlying titanium substrate, indicating that no secondary crystal phases were present. The other three samples had similar XRD patterns, with strong enhancement of the $\left(\begin{array}{lll}0 & 0\end{array}\right)$ peak and all peaks were identified as belonging to either the apatite crystal structure or the titanium substrate. In the thermal stability analysis shown below, the XRD patterns of HA, FHA, YHA, and YFHA 
samples are plotted with the $\left(\begin{array}{lll}0 & 0\end{array}\right)$ peak off scale in order to focus on the smaller peaks that result from the formation of secondary crystal phases upon heating.

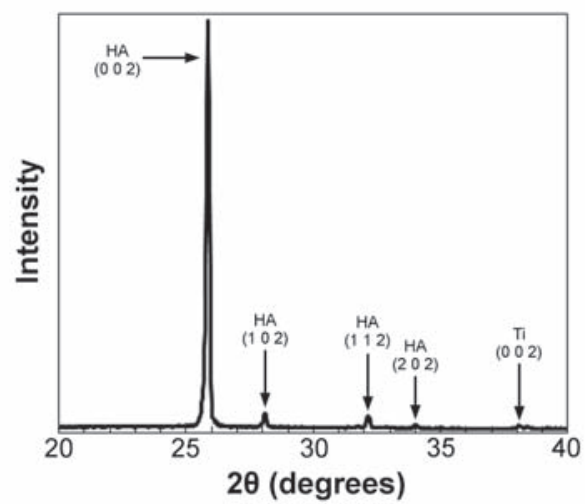

Figure 3: X-ray diffraction pattern of as-synthesized HA coating on titanium. Peaks are labeled with their corresponding Miller index number. Strong enhancement of the (002) peak indicates preferential orientation of the $c$-axis normal to the Ti surface.

Figure 4 shows the morphological changes observed upon heating samples of HA. The unheated sample shown in Fig. 4(a) has smooth surfaces with well defines crystal facets. Upon heating to $600{ }^{\circ} \mathrm{C}$ in dry air for 3 hours, as shown in Fig. 4(b), the crystal morphology was largely unchanged except for the appearance of a few small holes on some of the crystal facets. Increasing the heat treatment temperature to $700{ }^{\circ} \mathrm{C}$ in dry air results in the edges of the crystal facets becoming more rounded, and the formation of new smaller crystal grains embedded in the larger crystals, as shown in Fig. 4(c). Heating in dry air at $800{ }^{\circ} \mathrm{C}$ and $900{ }^{\circ} \mathrm{C}$ resulted in the crystals being entirely covered with new smaller crystal grains, as can be observed in Fig. 4(d) and Fig. 4(e). In contrast, Fig. 4(f) shows that HA can be heated up to $900{ }^{\circ} \mathrm{C}$ in a steam atmosphere without the crystal morphology changing. It is likely that steam suppresses the decomposition Reaction (1) via Le Chatelier's principle.

XRD analysis confirms that the morphological changes observed via SEM are the result of the formation of $\beta$-TCP. Figure 5 shows the XRD patterns of unheated HA in comparison to the sample exposed to steam at $900{ }^{\circ} \mathrm{C}$ for 3 hours, and HA samples exposed to dry air at $600,700,800$, and $900{ }^{\circ} \mathrm{C}$ for 3 hours. The XRD patterns of the samples heated in steam and in dry air at $600{ }^{\circ} \mathrm{C}$ appear very similar to that of unheated HA, which is consistent with the morphology of these samples all appearing similar in Fig. 4. For the sample heated in dry air at $700{ }^{\circ} \mathrm{C}$, a new 

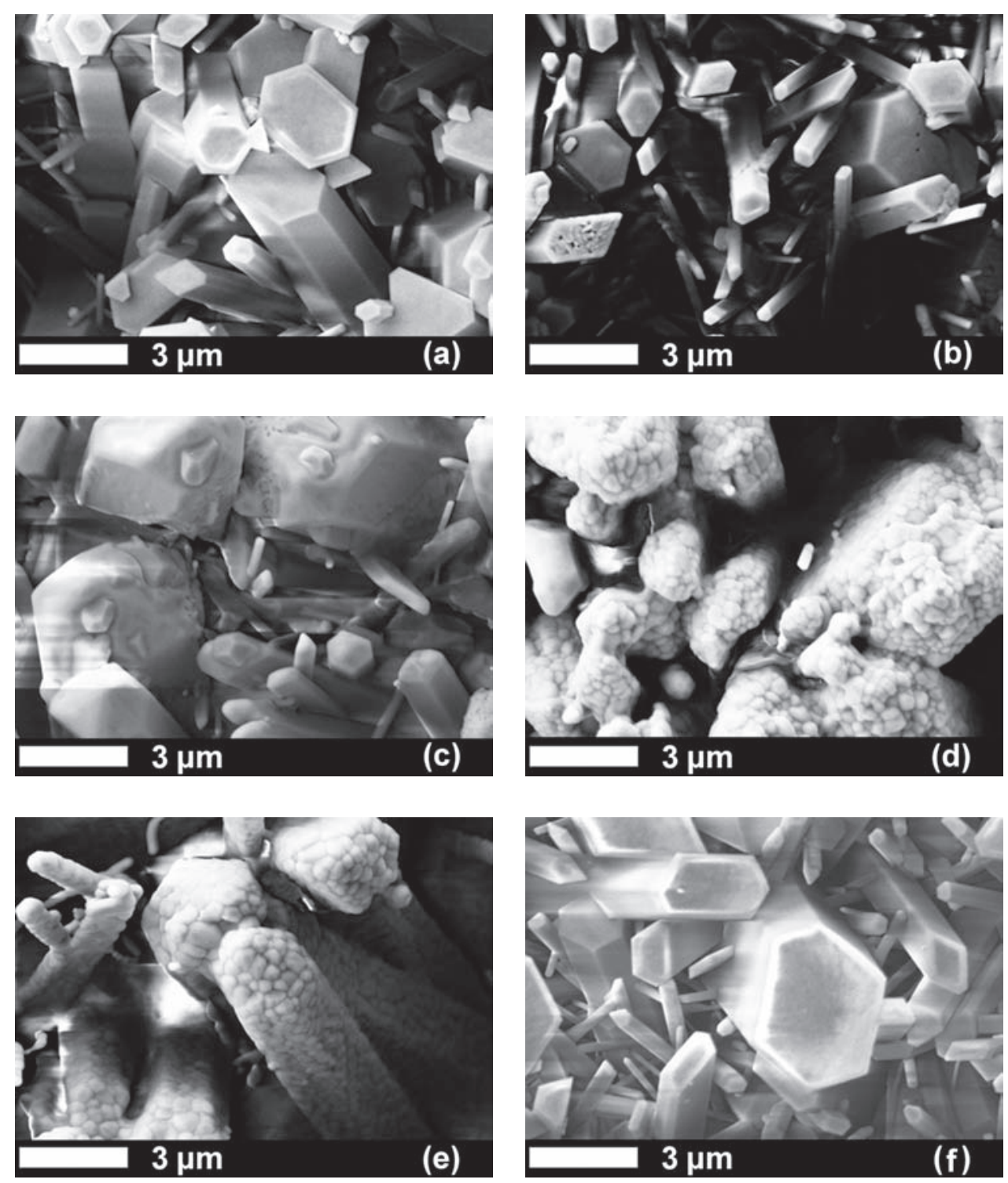

Figure 4: Hydroxyapatite (HA): (a) as-synthesized, (b) heated in dry air at $600{ }^{\circ} \mathrm{C}$, (c) heated in dry air at $700{ }^{\circ} \mathrm{C}$, (d) heated in dry air at $800{ }^{\circ} \mathrm{C}$, (e) heated in dry air at $900{ }^{\circ} \mathrm{C}$, (f) heated in steam at $900{ }^{\circ} \mathrm{C}$. 
peak appears that has been identified as the (0 2 10) peak of $\beta$-TCP according to JCPDS 09-0169. At higher temperatures, two additional peaks appear that have been identified as the (2 200$)$ and $\left(\begin{array}{lll}2 & 1 & 4\end{array}\right)$ peaks of $\beta$-TCP. The intensity of the $\beta$-TCP peaks increase with increasing temperature, indicating that the fraction of HA degrading to $\beta$-TCP in dry air increases with increasing temperature. The $\mathrm{XRD}$ patterns also confirm that steam is effective in preventing the degradation of HA to $\beta$-TCP.

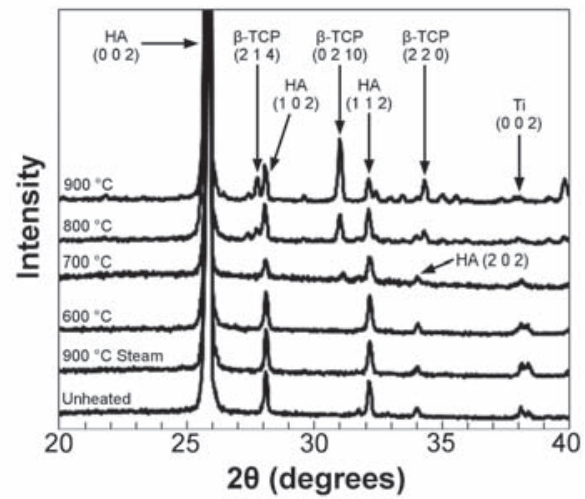

Figure 5: XRD patterns of hydroxyapatite (HA) samples: as-synthesized, heated in steam at 900 ${ }^{\circ} \mathrm{C}$, and heated in dry air at $600,700,800$, and $900{ }^{\circ} \mathrm{C}$.

Fluoride doping is also known to enhance the thermal stability of HA [40-43]. To examine the effect of fluoride doping on $\beta$-TCP formation, several samples of FHA were subjected to the same heat treatment process used for the HA samples described above. Figure 6 shows SEM images of unheated FHA in comparison to FHA samples heated in dry air at 700,800 , and $900{ }^{\circ} \mathrm{C}$ for 3 hours. The crystal morphology is largely unchanged. The edges of the crystal facets become slightly rounded upon heating, but there is no evidence of the formation of new crystal domains. XRD results support the SEM observations, as shown in Fig. 7. For all of the FHA samples, none of the $\beta$-TCP peaks found in heat treated HA were observed. The only XRD peaks not identified as belonging to apatite were those of the titanium substrate, or $\mathrm{TiO}_{2}$ as a result of surface oxidation of the substrate at high temperature in air. The results confirm the hypothesis that fluoride doping can enhance thermal stability of HA by preventing dehydroxylation.

Yttrium doping has been shown to significantly enhance proton conductivity of HA $[24,25]$. The trivalent yttrium ion substitutes for a fraction of the divalent calcium ions in the apatite crystal lattice. As a result, some of the $\mathrm{OH}^{-}$ions 

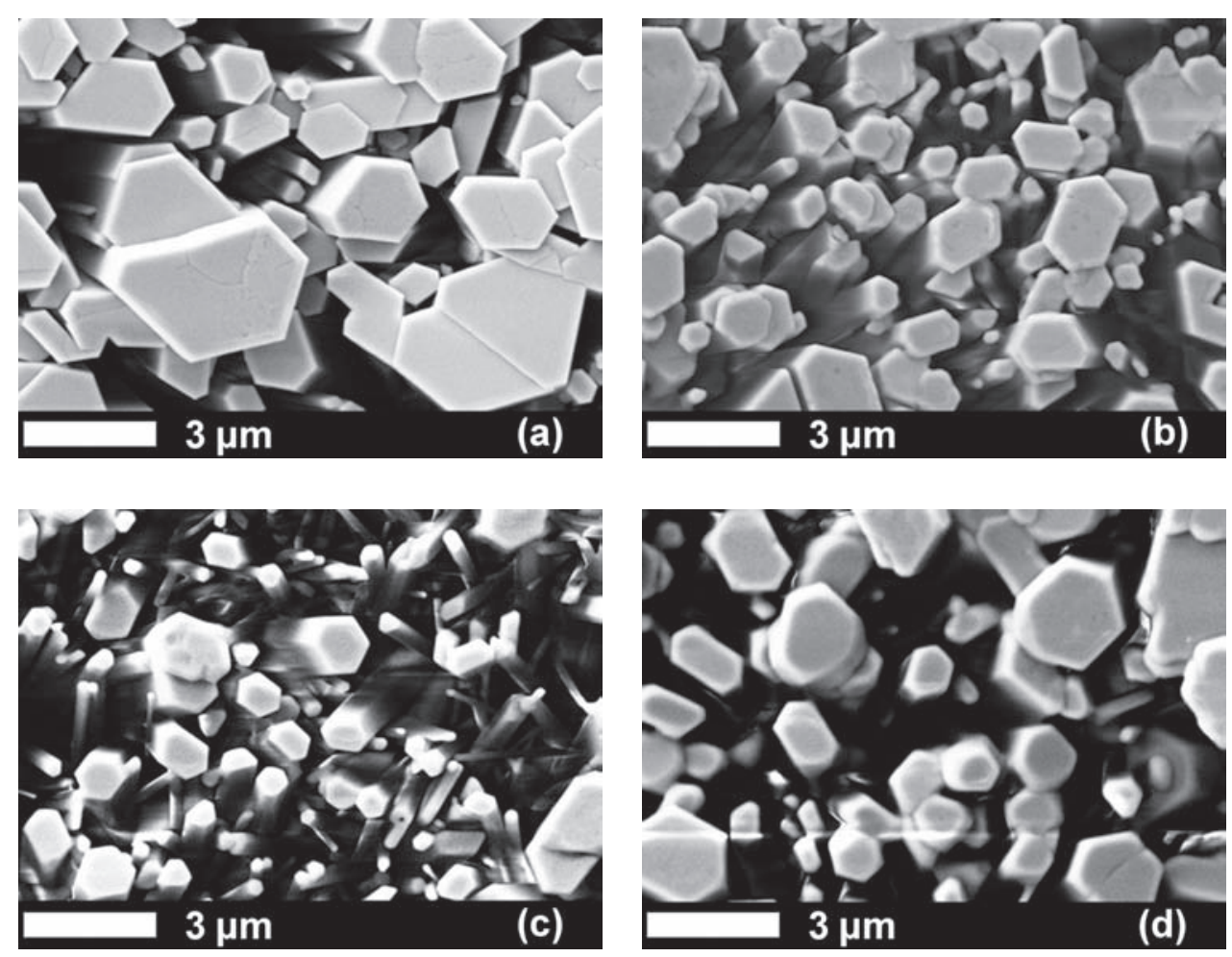

Figure 6: Fluoride doped hydroxyapatite (FHA) samples: (a) as synthesized, and heated in dry air at (b) $700{ }^{\circ} \mathrm{C}$, (c) $800{ }^{\circ} \mathrm{C}$, and (d) $900{ }^{\circ} \mathrm{C}$. 


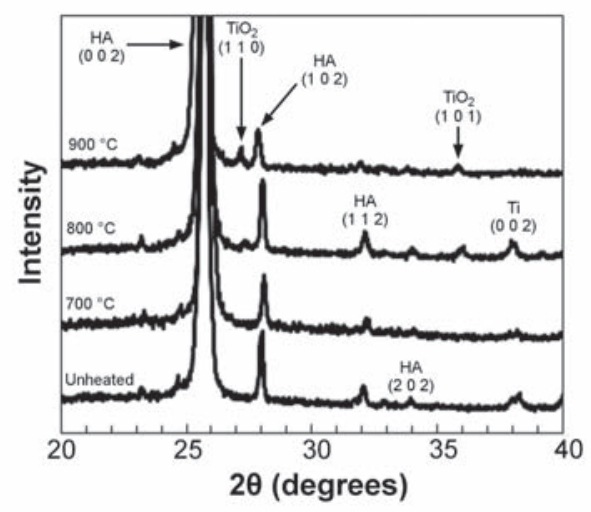

Figure 7: XRD patterns of fluoride doped hydroxyapatite (FHA) samples: as synthesized, and heated in dry air at 700,800 , and $900{ }^{\circ} \mathrm{C}$.

are converted to $\mathrm{O}^{2-}$ to maintain charge balance in the crystal. It has been hypothesized that the ratio of $\left[\mathrm{O}^{2-}\right] /\left[\mathrm{OH}^{-}\right]$plays a significant role in determining the conductivity [24]. Therefore, yttrium doping is of interest to create highly conductive HA membranes [25]. Unfortunately, yttrium doping was found to decrease thermal stability of HA. Figure 8 shows SEM images of unheated YHA in comparison to samples heated at $600,700,800$, and $900{ }^{\circ} \mathrm{C}$ for 3 hours. The crystals initially have smooth facets, but numerous grain boundaries are observed starting to form on the facets at $600{ }^{\circ} \mathrm{C}$. The new grains grow larger with increasing temperature. After heating at $900{ }^{\circ} \mathrm{C}$, the new grains cover the entire sample and it is difficult to discern the original YHA crystals from observation of the surface of the sample. The XRD patterns confirm that these new grains are from the formation of $\beta$-TCP, as seen in Fig. 8(f). For samples heated to $700-900{ }^{\circ} \mathrm{C}$ in dry air, the ( $\left.\begin{array}{lll}0 & 2 & 10\end{array}\right),\left(\begin{array}{lll}2 & 2 & 0\end{array}\right)$ and $\left(\begin{array}{lll}2 & 1 & 4\end{array}\right)$ peaks of $\beta$-TCP are observed, and the intensity of the $\beta$-TCP peaks increase with increasing temperature. It is apparent that yttrium doping decreases thermal stability, as the $\beta$-TCP grains start to form at a lower temperature and grow larger at higher temperatures than in un-doped HA processed under identical conditions.

To examine if fluoride doping may enhance thermal stability of YHA, samples co-doped with yttrium and fluoride were heated in dry air. Figure 9 shows SEM images of unheated YFHA in comparison to samples exposed to dry air at 800 and $900{ }^{\circ} \mathrm{C}$ for 3 hours. The coatings maintain the same dense morphology, with no evidence of the formation of new grains from the observation of the surface of the coating. The XRD patterns shown in Fig. 9(d) confirm that no $\beta$-TCP 

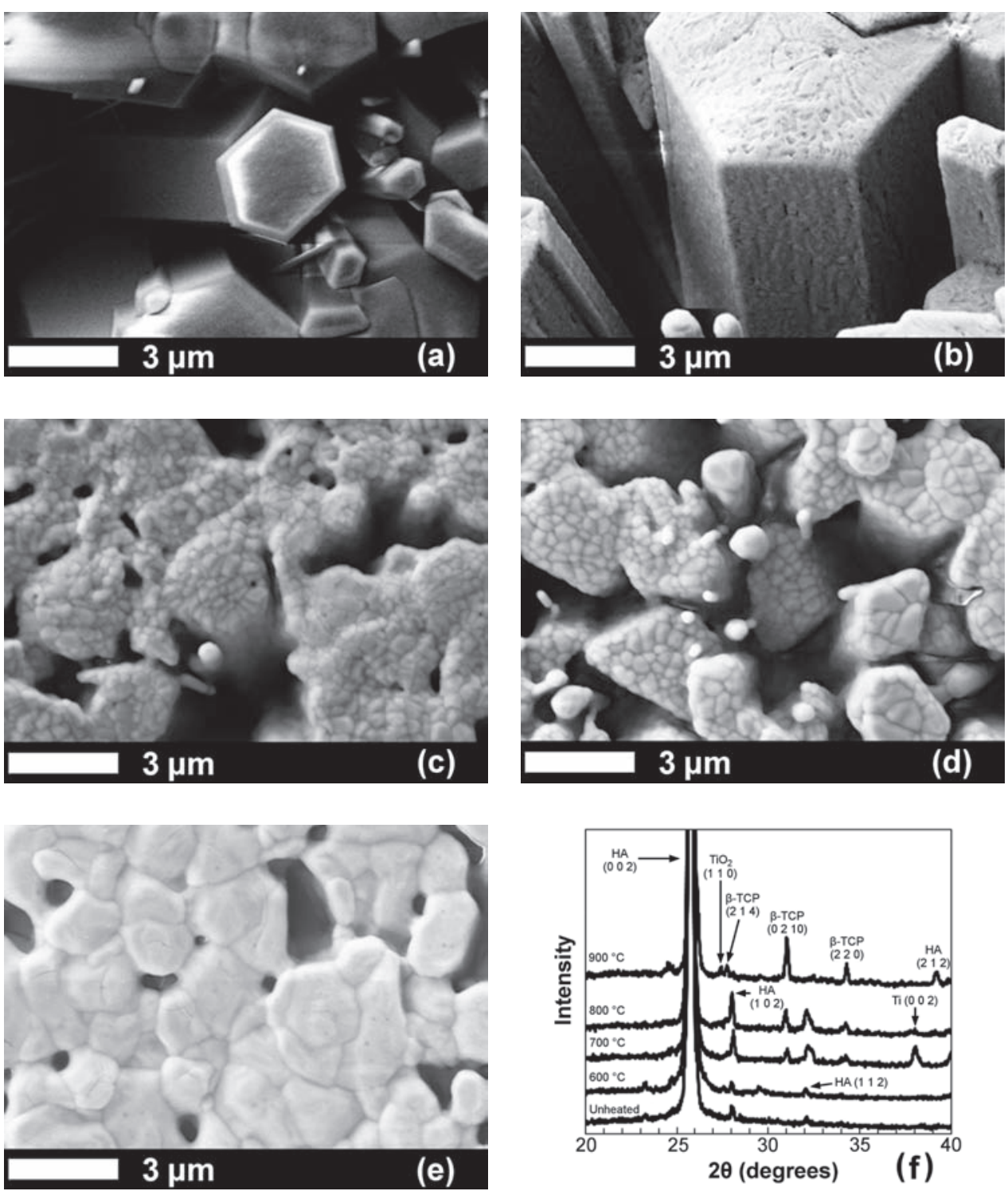

Figure 8: Yttrium doped hydroxyapatite (YHA) samples: (a) as synthesized, and heated in dry air at (b) $600{ }^{\circ} \mathrm{C}$, (c) $700{ }^{\circ} \mathrm{C}$, (d) $800{ }^{\circ} \mathrm{C}$, and (e) $900{ }^{\circ} \mathrm{C}$. XRD patterns of the samples are shown in (f). 

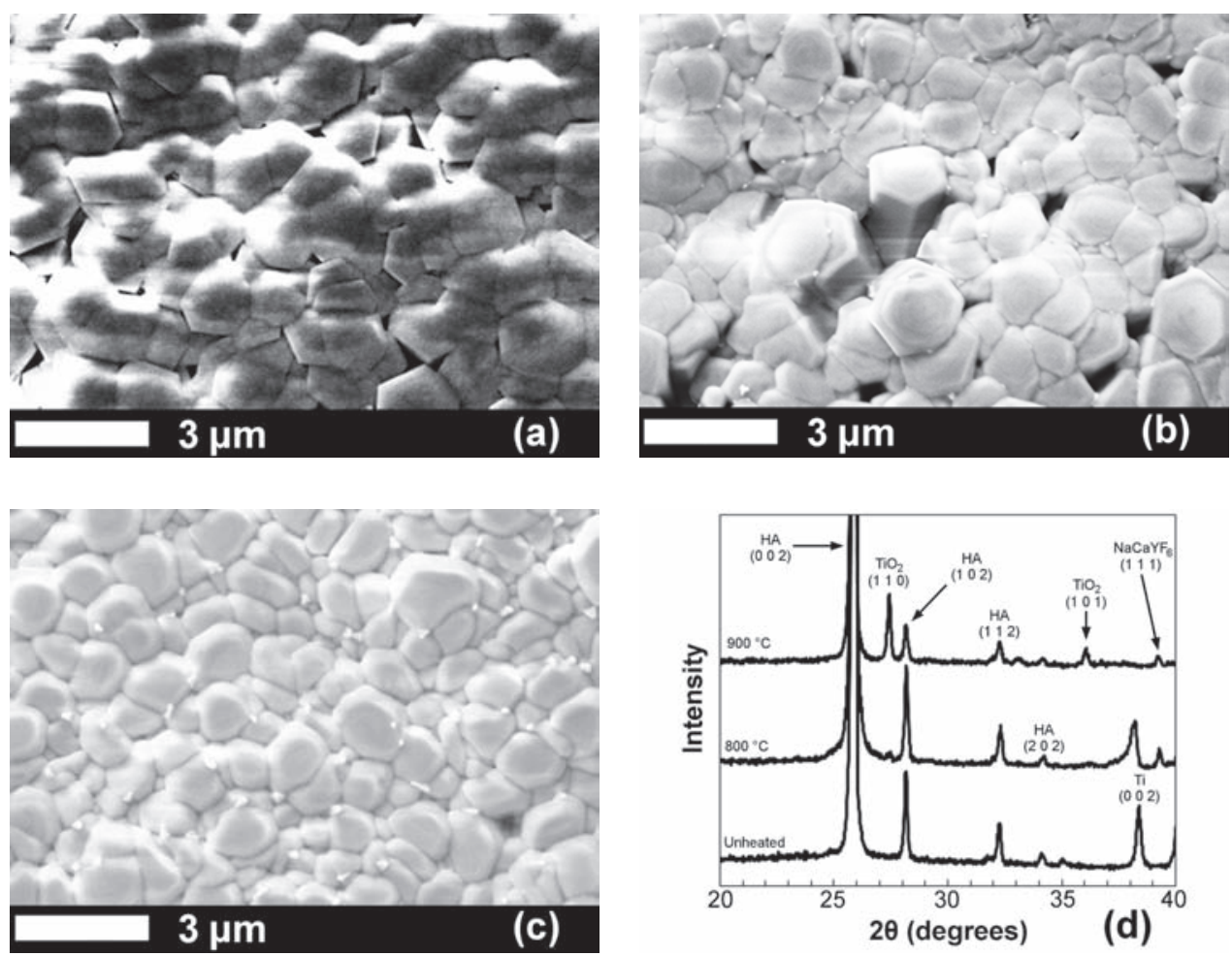

Figure 9: Yttrium/fluoride co-doped hydroxyapatite (YFHA) samples: (a) as synthesized, and heated in dry air at (b) $800{ }^{\circ} \mathrm{C}$ and (c) $900{ }^{\circ} \mathrm{C}$. XRD patterns of the samples are shown in (d).

peaks appear in the heated samples. The results indicate that fluoride doping significantly enhances thermal stability, even when the sample is co-doped with yttrium. The data also suggest that fluoride doping may be a broadly applicable approach to increase the thermal stability of apatite materials that are doped with other elements.

\section{Conclusions}

Electrochemical-hydrothermal synthesis produces HA coatings with a unique morphology consisting of crystal domains aligned with the $c$-axis normal to the substrate. As a result, the surface of the coating is covered extensively with crystallographic c-planes. The data show that the coatings are calcium deficient in composition, and decompose at high temperature through dehydroxylation to form a mixture of $\beta$-TCP and HA. Yttrium-doped HA is known to have higher 
ionic mobility than un-doped HA, but was found to be less thermally stable. The results suggest a connection between high temperature ionic mobility and thermal stability since ions are shuttled along the hydroxyl groups that are mobilized during dehydroxylation. The $\beta$-TCP grains grow to cover the coating surface. The formation of $\beta$-TCP and the introduction of grain boundaries between $\beta$-TCP and HA will hinder potential biomedical and electrochemical applications of the coatings.

Two methods were found to suppress thermal decomposition by preventing dehydroxylation that leads to $\beta$-TCP formation from calcium deficient HA: fluoride doping and added steam. The dehydroxylation reaction produces water vapor, and a steam atmosphere was found to suppress the reaction through Le Chatelier's principle. The hydroxyl groups were partially substituted with fluoride, and the presence of fluoride was found to suppress dehydroxylation. The unique coating morphology obtained through electrochemical-hydrothermal synthesis can therefore be maintained during high temperature applications and following thermal processing. The data demonstrate that fluoride doping and added steam enable the membrane morphology to be maintained at least up to a temperature of 900 ${ }^{\circ} \mathrm{C}$, which exceeds the typical operating temperatures of potential electrochemical applications of HA.

\section{Acknowledgments}

We acknowledge financial support from NSF (CMMI-0856128, IIP-1343083), the DOE through the Laboratory for Laser Energetics (DE-FC03-92SF19460) and the University of Rochester. We thank C. Pratt for assistance with XRD measurement.

\section{References}

[1] D. Haverty, S. a. M. Tofail, K. T. Stanton, J. B. McMonagle, Structure and stability of hydroxyapatite: Density functional calculation and rietveld analysis, Physical Review B 71 (9). doi:10.1103/PhysRevB.71.094103.

[2] M. J. Olszta, X. Cheng, S. S. Jee, R. Kumar, Y.-Y. Kim, M. J. Kaufman, E. P. Douglas, L. B. Gower, Bone structure and formation: A new perspective, Materials Science \& Engineering R-Reports 58 (3-5) (2007) 77-116. doi:10.1016/j.mser.2007.05.001. 
[3] C. Robinson, J. Kirkham, S. Brookes, W. Bonass, R. Shore, The chemistry of enamel development, International Journal of Developmental Biology 39 (1) (1995) 145-152, WOS:A1995QR86200013.

[4] S. Koutsopoulos, Synthesis and characterization of hydroxyapatite crystals: A review study on the analytical methods, Journal of Biomedical Materials Research 62 (4) (2002) 600-612. doi:10.1002/jbm.10280.

[5] S. Ban, S. Maruno, Hydrothermal-electrochemical deposition of hydroxyapatite, Journal of Biomedical Materials Research 42 (3) (1998) 387-395. doi:10.1002/(SICI)1097-4636(19981205)42:3<387::AID-JBM6>3.0.CO;2F.

[6] W. Suchanek, M. Yoshimura, Processing and properties of hydroxyapatitebased biomaterials for use as hard tissue replacement implants, Journal of Materials Research 13 (1) (1998) 94-117. doi:10.1557/JMR.1998.0015.

[7] B. Palazzo, M. Iafisco, M. Laforgia, N. Margiotta, G. Natile, C. L. Bianchi, D. Walsh, S. Mann, N. Roveri, Biomimetic hydroxyapatite-drug nanocrystals as potential bone substitutes with antitumor drug delivery properties, Advanced Functional Materials 17 (13) (2007) 2180-2188. doi:10.1002/adfm.200600361.

[8] K. Fox, P. A. Tran, N. Tran, Recent advances in research applications of nanophase hydroxyapatite, Chemphyschem 13 (10) (2012) 2495-2506. doi:10.1002/cphc.201200080.

[9] S. Bauer, P. Schmuki, K. von der Mark, J. Park, Engineering biocompatible implant surfaces part i: Materials and surfaces, Progress in Materials Science 58 (3) (2013) 261-326. doi:10.1016/j.pmatsci.2012.09.001.

[10] S. Bose, S. Tarafder, Calcium phosphate ceramic systems in growth factor and drug delivery for bone tissue engineering: A review, Acta Biomaterialia 8 (4) (2012) 1401-1421. doi:10.1016/j.actbio.2011.11.017.

[11] J. H. Shepherd, D. V. Shepherd, S. M. Best, Substituted hydroxyapatites for bone repair, Journal of Materials Science-Materials in Medicine 23 (10) (2012) 2335-2347. doi:10.1007/s10856-012-4598-2. 
[12] J. Weng, X. Liu, X. Li, X. Zhang, Intrinsic-factors of apatite influencing its amorphization during plasma-spray coating, Biomaterials 16 (1) (1995) 39-44. doi:10.1016/0142-9612(95)91094-F.

[13] A. E. Porter, S. M. Rea, M. Galtrey, S. M. Best, Z. H. Barber, Production of thin film silicon-doped hydroxyapatite via sputter deposition, Journal of Materials Science 39 (5) (2004) 1895-1898. doi:10.1023/B:JMSC.0000016213.77001.71.

[14] C. T. Kwok, P. K. Wong, F. T. Cheng, H. C. Man, Characterization and corrosion behavior of hydroxyapatite coatings on ti6al4 $\mathrm{v}$ fabricated by electrophoretic deposition, Applied Surface Science 255 (13-14) (2009) 67366744. doi:10.1016/j.apsusc.2009.02.086.

[15] M. Shirkhanzadeh, Calcium-phosphate coatings prepared by electrocrystallization from aqueous-electrolytes, Journal of Materials Science-Materials in Medicine 6 (2) (1995) 90-93. doi:10.1007/BF00120414.

[16] H. W. Kim, H. E. Kim, J. C. Knowles, Fluor-hydroxyapatite sol-gel coating on titanium substrate for hard tissue implants, Biomaterials 25 (17) (2004) 3351-3358. doi:10.1016/j.biomaterials.2003.09.104.

[17] P. Habibovic, F. Barrere, C. A. van Blitterswijk, K. de Groot, P. Layrolle, Biomimetic hydroxyapatite coating on metal implants, Journal of the American Ceramic Society 85 (3) (2002) 517-522.

[18] M. Roy, A. Bandyopadhyay, S. Bose, Induction plasma sprayed sr and $\mathrm{mg}$ doped nano hydroxyapatite coatings on ti for bone implant, Journal of Biomedical Materials Research Part B-Applied Biomaterials 99B (2) (2011) 258-265. doi:10.1002/jbm.b.31893.

[19] A. M. Ballo, W. Xia, A. Palmquist, C. Lindahl, L. Emanuelsson, J. Lausmaa, H. Engqvist, P. Thomsen, Bone tissue reactions to biomimetic ionsubstituted apatite surfaces on titanium implants, Journal of the Royal Society Interface 9 (72) (2012) 1615-1624. doi:10.1098/rsif.2011.0808.

[20] E. C. Moreno, M. Kresak, R. T. Zahradnik, Fluoridated Hydroxyapatite Solubility and Caries Formation, Nature 247 (5435) (1974) 64-65. doi:10.1038/247064a0. URL http://www . nature. com/doifinder/10.1038/247064a0 
[21] M. Larsen, S. Jensen, Solubility, unit cell dimensions and crystallinity of fluoridated human dental enamel, Archives of Oral Biology 34 (12) (1989) 969-973. doi:10.1016/0003-9969(89)90054-X. URL http://linkinghub.elsevier.com/retrieve/pii/000399698990054X

[22] C. J. Tredwin, A. M. Young, G. Georgiou, S.-H. Shin, H.-W. Kim, J. C. Knowles, Hydroxyapatite, fluor-hydroxyapatite and fluorapatite produced via the sol-gel method. Optimisation, characterisation and rheology, Dental Materials 29 (2) (2013) 166-173, wOS:000313745400007. doi:10.1016/j.dental.2012.11.008.

[23] O. A. Graeve, R. Kanakala, A. Madadi, B. C. Williams, K. C. Glass, Luminescence variations in hydroxyapatites doped with $\mathrm{Eu} 2+$ and $\mathrm{Eu} 3+$ ions, Biomaterials 31 (15) (2010) 4259-4267, wOS:000276932600002. doi:10.1016/j.biomaterials.2010.02.009.

[24] K. Yamashita, H. Owada, T. Umegaki, T. Kanazawa, K. Katayama, Protonic conduction in yttrium-substituted hydroxyapatite ceramics and their applicability to h2-o2 fuel-cell, Solid State Ionics 40-1 (1990) 918-921. doi:10.1016/0167-2738(90)90153-I.

[25] X. Wei, M. Z. Yates, Yttrium-doped hydroxyapatite membranes with high proton conductivity, Chemistry of Materials 24 (10) (2012) 1738-1743. doi:10.1021/cm203355h.

[26] D. Liu, K. Savino, M. Z. Yates, Microstructural engineering of hydroxyapatite membranes to enhance proton conductivity, Advanced Functional Materials 19 (24) (2009) 3941-3947. doi:10.1002/adfm.200900318.

[27] D. Liu, K. Savino, M. Z. Yates, Coating of hydroxyapatite films on metal substrates by seeded hydrothermal deposition, Surface \& Coatings Technology 205 (16) (2011) 3975-3986. doi:10.1016/j.surfcoat.2011.02.008.

[28] X. Wei, C. Fu, K. Savino, M. Z. Yates, Fully dense yttrium-substituted hydroxyapatite coatings with aligned crystal domains, Crystal Growth \& Design 12 (1) (2012) 217-223. doi:10.1021/cg200943s.

[29] X. Wei, C. Fu, K. Savino, M. Z. Yates, Carbonated hydroxyapatite coatings with aligned crystal domains, Crystal Growth \& Design 12 (7) (2012) 34743480. doi:10.1021/cg201685x. 
[30] C. Fu, K. Savino, P. Gabrys, A. Zeng, B. Guan, D. Olvera, C. Wang, B. Song, H. Awad, Y. Gao, M. Z. Yates, Hydroxyapatite thin films with giant electrical polarization, Chemistry of Materials in press.

[31] M. Aizawa, T. Matsuura, Z. Zhuang, Syntheses of Single-Crystal Apatite Particles with Preferred Orientation to the a- and c-Axes as Models of Hard Tissue and Their Applications, Biological \& Pharmaceutical Bulletin 36 (11) (2013) 1654-1661, wOS:000326359900002.

[32] S. Nakamura, H. Takeda, K. Yamashita, Proton transport polarization and depolarization of hydroxyapatite ceramics, Journal of Applied Physics 89 (10) (2001) 5386-5392. doi:10.1063/1.1357783.

[33] M. Andres-Verges, C. Fernandez-Gonzalez, M. Martinez-Gallego, J. D. Solier, I. Cachadina, E. Matijevic, A new route for the synthesis of calciumdeficient hydroxyapatites with low ca/p ratio: Both spectroscopic and electric characterization, Journal of Materials Research 15 (11) (2000) 25262533. doi:10.1557/JMR.2000.0362.

[34] Y. Tanaka, M. Nakamura, A. Nagai, T. Toyama, K. Yamashita, Ionic conduction mechanism in ca-deficient hydroxyapatite whiskers, Materials Science and Engineering B-Advanced Functional Solid-State Materials 161 (13) (2009) 115-119. doi:10.1016/j.mseb.2009.01.016.

[35] Y. Tanaka, T. Iwasaki, M. Nakamura, A. Nagai, K. Katayama, K. Yamashita, Polarization and microstructural effects of ceramic hydroxyapatite electrets, Journal of Applied Physics 107 (1) (2010) 014107. doi:10.1063/1.3265429.

[36] K. Yamashita, K. Kitagaki, T. Umegaki, Thermal-instability and proton conductivity of ceramic hydroxyapatite at high-temperatures, Journal of the American Ceramic Society 78 (5) (1995) 1191-1197. doi:10.1111/j.11512916.1995.tb08468.x.

[37] S. Raynaud, E. Champion, D. Bernache-Assollant, P. Thomas, Calcium phosphate apatites with variable $\mathrm{ca} / \mathrm{p}$ atomic ratio i. synthesis, characterisation and thermal stability of powders, Biomaterials 23 (4) (2002) 1065-1072. doi:10.1016/S0142-9612(01)00218-6.

[38] G. Maiti, F. Freund, Influence of fluorine substitution on the proton conductivity of hydroxyapatite, Journal of the Chemical Society-Dalton Transactions (4) (1981) 949-955. doi:10.1039/dt9810000949. 
[39] K.-S. Lee, C. J. Hwang, J.-H. Kim, H.-S. Lee, H.-S. Ryu, J.-S. Chang, D.-H. Lee, Study of Difference in Biodegradation Mechanism on the Surface of Hydroxyapatite and beta-Tricalcium Phosphate, Science of Advanced Materials 6 (10) (2014) 2238-2243, wOS:000345062900022. doi:10.1166/sam.2014.2073.

[40] Y. M. Chen, X. G. Miao, Thermal and chemical stability of fluorohydroxyapatite ceramics with different fluorine contents, Biomaterials 26 (11) (2005) 1205-1210. doi:10.1016/j.biomaterials.2004.04.027.

[41] H. Zhao, F. Wang, X. Chen, Z. Wei, D. Yu, Z. Jiang, The formation mechanism of the beta-TCP phase in synthetic fluorohydroxyapatite with different fluorine contents, Biomedical Materials 5 (4) (2010) 045011. doi:10.1088/1748-6041/5/4/045011.

[42] S. Nasr, E. Ben Salem, H. Boughzala, K. Bouzouita, Effect of fluorine on the thermal stability of the magnesium-substituted hydroxyapatite, Annales De Chimie-Science Des Materiaux 36 (3) (2011) 159-176.

[43] Y. Cai, S. Zhang, X. Zeng, D. Sun, Effect of fluorine incorporation on long-term stability of magnesium-containing hydroxyapatite coatings, Journal of Materials Science-Materials in Medicine 22 (7) (2011) 1633-1638. doi:10.1007/s10856-011-4348-x.

[44] R. K. Roeder, G. L. Converse, H. J. Leng, W. M. Yue, Kinetic effects on hydroxyapatite whiskers synthesized by the chelate decomposition method, Journal of the American Ceramic Society 89 (7) (2006) 2096-2104. doi:10.1111/j.1551-2916.2006.01067.x. 